\title{
Aleitamento materno: prevalência e caracterização da informação prestada
}

Nadina Sousa, Ana Carla Bernardes*

\section{RESUMO}

Objectivos: Caracterizar a informação recebida pelas puérperas sobre aleitamento materno. Caracterizar o tipo de aleitamento realizado durante o internamento. Conhecer as razões que levaram à adopção ou não do aleitamento materno e as principais dificuldades na sua implementação.

Tipo de estudo: Observacional, descritivo, transversal.

Local: Serviço de Obstetrícia do Hospital de Santo André, E.P.E., Leiria.

População: Puérperas internadas no referido serviço.

Métodos: Foi aplicado, por entrevista directa, um questionário pré-testado, no período de quatro semanas, entre Dezembro de 2007 e Janeiro de 2008. Foram estudadas variáveis de caracterização das puérperas, do seguimento da gravidez, informação recebida e aleitamento adoptado. Foram excluídas as puérperas que recusassem participar, aquelas com incapacidade de responder por razões linguísticas, as puérperas internadas no serviço por complicações tardias do puerpério e as puérperas às quais não foi possível realizar a entrevista em tempo útil.

Resultados: Foram incluídas 164 puérperas, das quais 63\% afirmaram ter recebido informação sobre aleitamento materno. As fontes de informação mais frequentes foram o enfermeiro e o médico. Quanto à classificação da informação, os pontos mais positivos foram a clareza e a possibilidade em esclarecer dúvidas. O tempo despendido e o número de intervenções foram insuficientes em $11,8 \%$ e $10,8 \%$, respectivamente. A prevalência de aleitamento materno foi de $95,1 \%$ e a razão mais frequente para a sua escolha foi o benefício para o lactente. Das puérperas a fazer aleitamento materno, $47,4 \%$ referiram dificuldades com a sua implementação.

Conclusão: Este estudo mostra a necessidade de reforço da informação prestada sobre aleitamento materno pelos profissionais de saúde. Destaca-se por caracterizar os parâmetros da informação a melhorar e as dificuldades das puérperas, permitindo planear a actuação na gravidez e período pós-natal.

Palavras-chave: Aleitamento Materno; Aconselhamento; Prevalência.

\section{INTRODUÇÃO}

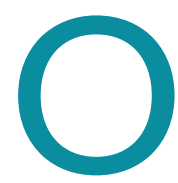

aleitamento materno tem vários benefícios comprovados, não só para o lactente e para a mãe, mas também económicos e ambientais.

Das várias vantagens comprovadas para o recém-nascido, destacam-se as nutricionais, imunológicas, gastrointestinais e de prevenção de doenças em idade pediátrica e adulta, nomeadamente hipertensão arterial, dislipidémia, obesidade, diabetes tipo 1 e 2, doença celíaca, doença inflamatória intestinal, neoplasias e

*Assistente de Medicina Geral e Familiar, CS Arnaldo Sampaio, Leiria. as manifestações de atopia..$^{1-8}$ Também se verificam vantagens a nível do desenvolvimento intelectual e do estabelecimento da relação de vinculação mãe-filho. ${ }^{1,2}$

A evidência científica demonstrou ainda as vantagens da amamentação para a saúde da mãe, não só na mais rápida recuperação no pós-parto, mas também na prevenção do cancro da mama e do ovário, redução da osteoporose pós-menopáusica e como método contraceptivo natural. ${ }^{2,3}$

Finalmente, a nível económico e ambiental, o aleitamento materno é gratuito, prático e não gera desperdícios, consumo de energia e formação de resíduos com a produção, embalagem e transporte. ${ }^{2}$ 
A Organização Mundial de Saúde (OMS) em conjunto com o Fundo das Nações Unidas para a Infância (UNICEF), na sua publicação «Global Strategy for Infant and Young Child Feeding», bem como o programa governamental «Healthy People 2010», dos Estados Unidos da América (EUA), recomendam o aleitamento materno exclusivo até aos 6 meses, com manutenção, pelo menos, até aos 2 anos. Estas recomendações são também partilhadas pela Academia Americana de Pediatria e pela Sociedade Canadiana de Pediatria. $1^{1,9,10}$

Em Portugal, a prevalência de aleitamento materno à alta da maternidade varia de acordo com os estudos, entre os $85 \%{ }^{11}$ e os 91 a $98,5 \%,{ }^{2,3,12,13}$ com amamentação em exclusividade em $77,7 \%$ dos casos. ${ }^{3}$ No entanto, estes valores decaem progressivamente, atingindo valores entre os 34,1 e os $36 \%$ aos 6 meses, bem abaixo da meta de $50 \%$ definida pela OMS. ${ }^{2,3,12,13}$

Os factores associados a uma maior prevalência de aleitamento materno na literatura são a idade, estrato social e nível de escolaridade maternos, ${ }^{2,3,14}$ a intenção de amamentar, ${ }^{14,15}$ bem como a informação e aconselhamento pré-natal e as medidas de apoio pós-natal. ${ }^{16}$ ${ }^{19}$ Das medidas de apoio pós-natal fazem parte as práticas hospitalares promotoras do aleitamento materno, nomeadamente as previstas nos Hospitais Amigos dos Bebés, e também o acompanhamento das mães nas consultas de Saúde Infantil, Puerpério e Vacinação. Em Portugal, a Direcção-Geral da Saúde recomenda o aconselhamento sobre aleitamento materno a partir das 20 semanas e até ao parto.

A decisão de amamentar é pessoal, mas o sucesso do aleitamento materno depende da informação e apoio que a mulher recebe no período pré e pós-natal.

Os objectivos deste trabalho são: 1) caracterizar a informação recebida pelas puérperas sobre aleitamento materno, quanto à fonte, momento, número de intervenções e clareza da informação transmitida; 2) caracterizar o tipo de aleitamento realizado durante o internamento; 3) conhecer as razões que levaram à adopção ou não do aleitamento materno; e 4) conhecer as principais dificuldades na sua implementação, durante o internamento.

\section{MÉTODOS}

A população estudada foi constituída pelas puérperas internadas no Serviço de Obstetrícia do Hospital de
Santo André, E.P.E., Leiria. Foi escolhida uma amostra de conveniência, que compreendeu todas as puérperas internadas $(\mathrm{n}=180)$ durante um período de quatro semanas, de 10/12/2007 a 11/01/2008.

Foi realizado um estudo observacional, descritivo, transversal. As unidades de observação foram os questionários, aplicados por entrevista, com uma pergunta de autopreenchimento.

Neste estudo foram definidas as seguintes variáveis:

- Caracterização sociodemográfica e antecedentes obstétricos das puérperas:

- Idade

- Concelho de residência

- Habilitações literárias

- Situação laboral

- Profissão

- Estado civil

- Tipo de família

- Escala de Graffar modificada

- Paridade

- Amamentação anterior

- Caracterização do seguimento da gravidez:

- Local de seguimento (Centro de Saúde, Hospital, Obstetra particular)

- Existência de consulta pré-concepcional

- Número de consultas na gravidez

- Duração da gestação

- Tipo de parto

- Caracterização da informação recebida:

- Ocorrência de informação sobre aleitamento materno

- Fontes de informação

- Momento da gestação em que ocorreu

- Classificação da informação (1 - Muito insuficiente; 2 - Insuficiente; 3 - Suficiente; 4 - Bom; 5 - Muito bom):

- Clareza da informação prestada

- Tempo despendido

- Número de vezes que o assunto foi abordado

- Possibilidade de esclarecer dúvidas

- Caracterização do aleitamento adoptado:

- Intenção de aleitamento antes do parto

- Aleitamento realizado no internamento

- Razões da escolha efectuada

- Dificuldades de adaptação ao leite materno

Definiu-se aleitamento materno como a alimenta- 
ção do lactente com leite materno, directamente da mama ou extraído. Quanto ao aleitamento materno exclusivo, aplicou-se nas situações em que o lactente foi alimentado apenas com leite materno, admitindo-se ainda a administração de vitaminas, suplementos minerais ou fármacos. ${ }^{20}$

Quanto às razões para a escolha do tipo de aleitamento, era pedido a cada puérpera que indicasse quais as razões mais importantes para si, num máximo de três.

Para a recolha de dados, utilizou-se um questionário que foi pré-testado em cinco puérperas internadas no serviço, que não foram incluídas na amostra. O questionário continha perguntas fechadas e abertas, e foi aplicado por meio de entrevista, com uma pergunta de autopreenchimento. As entrevistas foram realizadas pela primeira autora do estudo, nos dias úteis, em data próxima da alta.

Antes do início do estudo foi obtida autorização formal do Director de Serviço. Foi obtido o consentimento informado, de forma oral, junto de cada participante ou seu representante, antes da realização da entrevista, pela primeira autora do estudo.

Foram incluídas todas as puérperas internadas no serviço. Excluíram-se as puérperas que recusassem participar, aquelas com incapacidade de realização da entrevista por razões linguísticas, as puérperas internadas no serviço por complicações tardias do puerpério e as puérperas às quais não fosse possível realizar a entrevista em tempo útil.

Os dados obtidos foram codificados e introduzidos na matriz de dados, sendo depois tratados com a aplicação informática de estatística SPSS $15.0^{\circledR} \mathrm{e}$ a folha de cálculo Excel $2003^{\circledR}$.

\section{RESULTADOS}

Durante o período de estudo, estiveram internadas 180 puérperas no Serviço.

Foram excluídas: uma puérpera internada por complicações tardias do puerpério, uma por recusa em participar, duas por dificuldades linguísticas e doze por não ser possível realizar a entrevista em tempo útil.

Foram incluídas 164 puérperas, valor que corresponde a $91,6 \%$ das puérperas internadas no período e a $6,6 \%$ dos partos realizados por ano nesta maternidade (2470 partos em 2007).

\section{Caracterização sociodemográfica e antecedentes obstétricos}

As características sociodemográficas das puérperas avaliadas estão resumidas no Quadro I.

A idade variou entre os 17 e os 42 anos, com uma média de 29,5 $( \pm 5,1)$ anos. O grupo etário mais prevalente foi o dos 30-34 anos, com 66 puérperas, como se mostra na Figura 1. Destacam-se uma puérpera adolescente e 22 com idade igual ou superior a 35 anos.

A maior parte das puérperas residia no concelho de Leiria $(40,9 \%)$, mas $20,7 \%$ provinham de fora do distrito.

Quanto às habilitações literárias, $19,5 \%$ das inquiridas não tinham a escolaridade obrigatória, enquanto $22,6 \%$ tinham uma licenciatura.

A maioria das puérperas eram trabalhadoras no activo $(75,0 \%)$, mas $26,8 \%$ tinham uma profissão indiferenciada.

A maior parte das inquiridas pertencia à classe média-baixa $(38,4 \%)$.

Quanto ao estado civil, 68,9\% das inquiridas eram casadas, sendo que o tipo de família mais frequente era o nuclear $(88,4 \%)$.

A maioria das puérperas era primípara, com $44,5 \%$ de primíparas primigestas. Das multíparas (74), 89,2\% tinha amamentado anteriormente, durante uma média

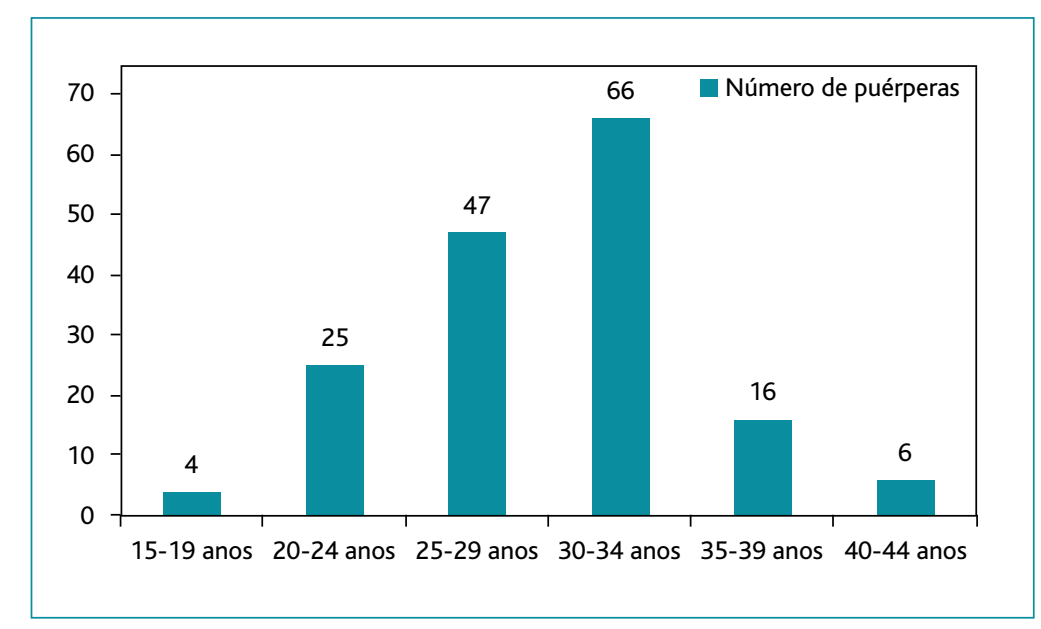

Figura 1. Distribuição das puérperas por grupo etário. 
de 6,4 meses ( \pm 4,3 meses), variando entre os 15 dias e os 18 meses.

\section{Caracterização do seguimento da gravidez}

A maioria das puérperas $(56,1 \%)$ foi seguida por obstetra particular; $22,6 \%$ foram seguidas apenas no Centro de Saúde e 6,1\% foram seguidas simultaneamente no Centro de Saúde e no Hospital, conforme se observa no gráfico da Figura 2.

Verificaram-se duas gravidezes não vigiadas e três mal vigiadas, ou seja, com número de consultas realizadas inferior a seis, de acordo com as recomendações da Direcção-Geral da Saúde.

Quanto à consulta pré-concepcional, foi realizada por 72 inquiridas (43,9\%). Destas, 49 foram realizadas por obstetra particular, 17 no Centro de Saúde, três simultaneamente no Centro de Saúde e obstetra particular e três no Hospital.

Foram registados 152 partos de termo $(92,7 \%)$ e $12(7,3 \%)$ partos pré-termo.

\section{Caracterização da informação recebida}

Quanto à informação sobre aleitamento materno, 102 inquiridas $(62,2 \%)$ afirmaram ter recebido algum tipo de informação durante a gravidez ou na maternidade. A caracterização dessa informação, quanto às fontes e aos momentos em que teve lugar, é apresentada no Quadro II.

A fonte de informação mais frequente foi o enfermeiro, referido por 89 puérperas, seguido do médico (61), dos meios de comunicação e folhetos de puericultura (41) e, por último, dos familiares ou amigos (31).

Essa informação ocorreu preferencialmente na maternidade (71) e a partir do segundo trimestre de gestação.

\section{Classificação da informação recebida}

A clareza da informação foi considerada Muito Boa por $40 \%$ (41/102) das puérperas e Boa por $42 \%$ (43/102); apenas $1 \%(1 / 102)$ consideraram a informação Insuficiente e Muito Insuficiente, para ambos os parâmetros.

\begin{tabular}{|c|c|c|}
\hline Variáveis & & Resultados \\
\hline Idade (média \pm dp) (anos) & & $29,5 \pm 5,1$ \\
\hline Máximo & & 42 \\
\hline Mínimo & & 17 \\
\hline \multirow[t]{9}{*}{ Concelho de residência } & Leiria & $40,9 \%$ \\
\hline & Marinha Grande & $1,8 \%$ \\
\hline & Porto de Mós & $7,3 \%$ \\
\hline & Ourém & $11,0 \%$ \\
\hline & Batalha & $6,1 \%$ \\
\hline & Pombal & $10,4 \%$ \\
\hline & Alcobaça & $1,2 \%$ \\
\hline & Nazaré & $0,6 \%$ \\
\hline & Fora do Distrito & $20,7 \%$ \\
\hline \multirow[t]{5}{*}{ Habilitações literárias } & 4. ${ }^{\circ}$ Ano & $6,7 \%$ \\
\hline & $6 .^{\circ}$ Ano & $12,8 \%$ \\
\hline & 9. ${ }^{\circ}$ Ano & $25,0 \%$ \\
\hline & Secundário & $32,9 \%$ \\
\hline & Licenciatura & $22,6 \%$ \\
\hline \multirow[t]{4}{*}{ Situação laboral } & Trabalhadora no activo & $75,0 \%$ \\
\hline & Doméstica & $11,0 \%$ \\
\hline & Desempregada & $12,2 \%$ \\
\hline & Estudante & $1,8 \%$ \\
\hline \multirow[t]{6}{*}{ Profissão (Escala Graffar) } & $1 .^{\circ}$ grau & $1,2 \%$ \\
\hline & 2. ${ }^{\circ}$ grau & $18,9 \%$ \\
\hline & 3. ${ }^{\circ}$ grau & $15,2 \%$ \\
\hline & 4. ${ }^{\circ}$ grau & $12,8 \%$ \\
\hline & 5. grau & $26,8 \%$ \\
\hline & Não aplicável & $25,0 \%$ \\
\hline \multirow[t]{4}{*}{ Escala de Graffar adaptada } & Média-Alta & $17,7 \%$ \\
\hline & Média & $23,8 \%$ \\
\hline & Média-Baixa & $38,4 \%$ \\
\hline & Baixa & $20,1 \%$ \\
\hline \multirow[t]{5}{*}{ Estado civil } & Casada & $68,9 \%$ \\
\hline & União de facto & $4,3 \%$ \\
\hline & Solteira & $3,7 \%$ \\
\hline & Divorciada & $22,6 \%$ \\
\hline & Viúva & $0,6 \%$ \\
\hline \multirow[t]{5}{*}{ Tipo de família } & Nuclear & $88,4 \%$ \\
\hline & Reconstruída & $4,3 \%$ \\
\hline & Monoparental & $3,0 \%$ \\
\hline & Alargada & $3,0 \%$ \\
\hline & Outra & $1,2 \%$ \\
\hline \multirow[t]{4}{*}{ Paridade } & Primípara primigesta & $44,5 \%$ \\
\hline & Primípara não primigesta & $10,4 \%$ \\
\hline & Multípara & $40,9 \%$ \\
\hline & Grande multípara & $4,3 \%$ \\
\hline \multirow{2}{*}{$\begin{array}{l}\text { Amamentação anterior } \\
(n=74)\end{array}$} & Sim & $89,2 \%$ \\
\hline & Não & $10,8 \%$ \\
\hline
\end{tabular}




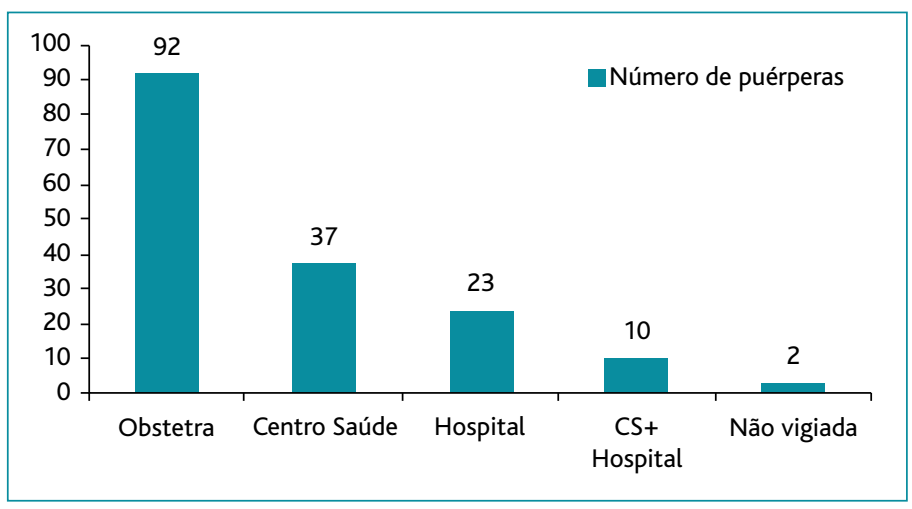

Figura 2. Local de seguimento da gestação. Legenda: CS, Centro de Saúde. clarecer dúvidas foi classificada como Muito Boa por $54 \%$ (55/102) e Boa por $32 \%$ (33/102) das inquiridas; apenas $1 \%(1 / 102)$ das puérperas considerou este parâmetro Muito Insuficiente.

Os resultados apresentam-se no gráfico da Figura 3.

\section{Caracterização do aleitamento adoptado}

Quanto à intenção de aleitamento antes do parto, 94,5\% (155/164) das puérperas planearam realizar aleitamento materno exclusivo, enquanto $2,4 \%(4 / 164)$ planearam realizar aleitamento artificial; 2,4\% (4/164) não planearam o tipo de aleitamento.

\begin{tabular}{|c|c|c|}
\hline \multicolumn{3}{|c|}{$\begin{array}{l}\text { QUADRO II. Caracterização da informação sobre } \\
\text { aleitamento materno, quanto às fontes e aos } \\
\text { momentos em que teve lugar ( } n=102) \text {. }\end{array}$} \\
\hline \multicolumn{2}{|c|}{ Informação sobre aleitamento materno } & \multirow{2}{*}{$\begin{array}{r}\text { Resultados } \\
87,3 \%\end{array}$} \\
\hline Fontes & Enfermeiro & \\
\hline & Médico & $59,8 \%$ \\
\hline & Meios de Comunicação & $40,2 \%$ \\
\hline & Familiares e/ou Amigos & $30,4 \%$ \\
\hline \multirow[t]{6}{*}{ Momento } & Pré-concepcional & $1,0 \%$ \\
\hline & Curso de Preparação & $21,6 \%$ \\
\hline & 1. ${ }^{\circ}$ Trimestre & $31,4 \%$ \\
\hline & 2. ${ }^{\circ}$ Trimestre & $50,0 \%$ \\
\hline & 3. ${ }^{\circ}$ Trimestre & $67,6 \%$ \\
\hline & Maternidade & $69,6 \%$ \\
\hline
\end{tabular}

A prevalência de aleitamento materno foi de $95,1 \%$ (156/164), com $18,3 \%(30 / 164)$ das puérperas a fazer aleitamento misto e 4,9\% (8/164) das puérperas a realizarem aleitamento artificial. Os resultados da intenção de aleitamento e tipo de aleitamento realizado são apresentados no gráfico da Figura 4.

Quanto às razões para a adopção do leite materno, foram apontadas 451 razões, com uma média de 2,9 razões por puérpera. As vantagens para o bebé foram as mais apontadas, contabilizando $74,1 \%(334 / 451)$, seguidas das vantagens para a mãe, com 14,8\% (67/451), e de outras razões, com 11,1\% (50/451). A razão mais frequente foi a «imunidade», referida por $73,1 \%$ das puérperas (114/156), seguida do "crescimento", mencionada por $66,7 \%$ das inquiridas (104/156), e das vantagens «nutricionais», apontadas por $63,5 \%$ (99/156). Os

O tempo despendido foi considerado Muito Bom por 32\% (33/102) das inquiridas e Bom por $33 \%$ (34/102); no entanto, $11 \%(11 / 102)$ das puérperas consideraram este parâmetro Insuficiente e 1\% (1/102) Muito Insuficiente.

O número de intervenções foi considerado Muito Bom por $31 \%$ (32/102) e Bom por $26 \%(27 / 102)$ das inquiridas, mas apenas como Insuficiente por 9\% (9/102) e Muito Insuficiente por $2 \%(2 / 102)$ das puérperas.

Finalmente, a possibilidade de es-

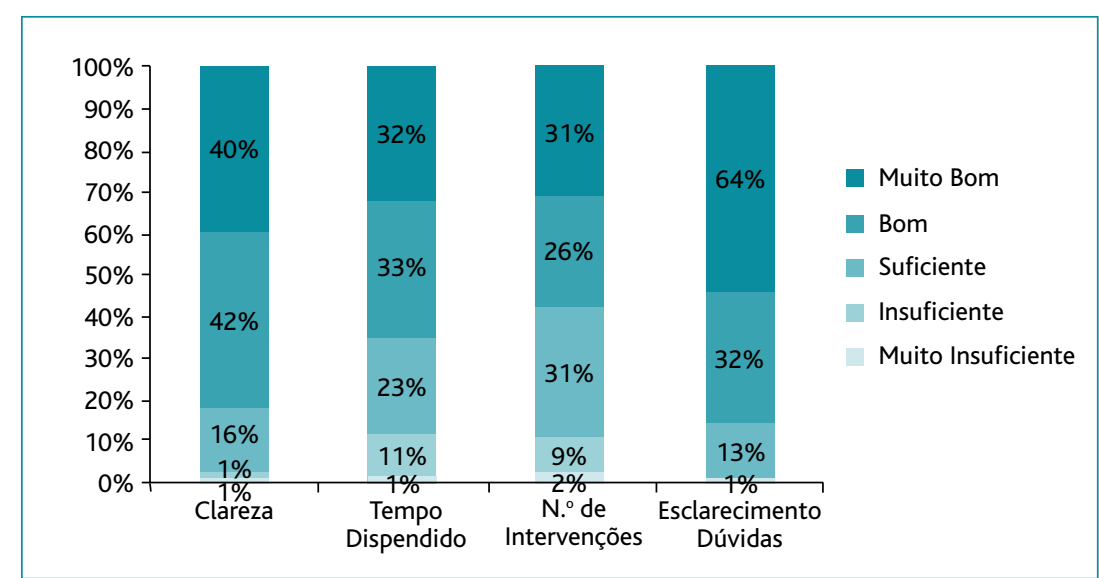

Figura 3. Classificação da informação sobre aleitamento materno. 


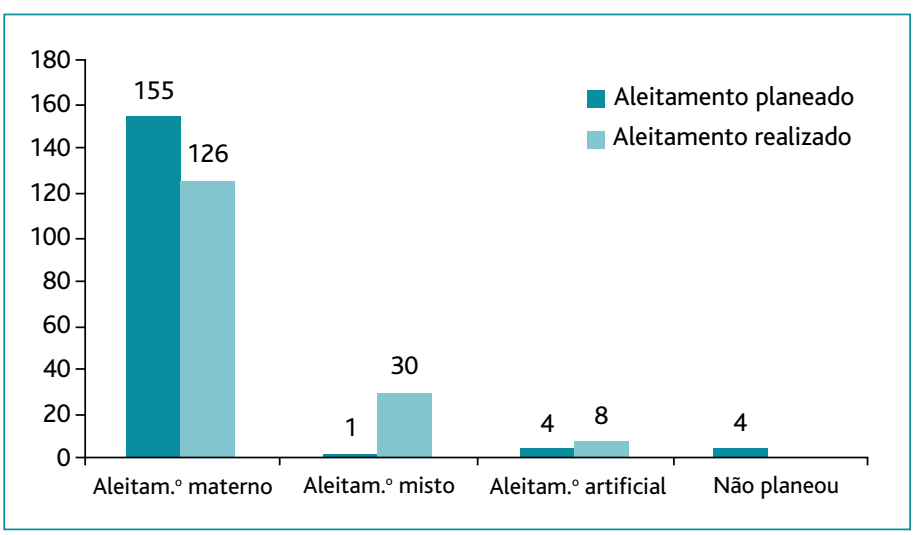

Figura 4. Intenção de aleitamento antes do parto e tipo de aleitamento realizado até à alta da maternidade.

resultados são apresentados no Quadro III.

Quanto ao leite artificial, 92,1\% das puérperas $(35 / 38)$ fazia leite artificial por dificuldades de adaptação ao leite materno e 7,9\% (3/38) por necessidade de tomar medicação que contra-indicava o aleitamento. Nestes três casos, a contra-indicação foi comprovada medicamente.

Quando inquiridas, 47,4\% (74/156) das puérperas a fazer aleitamento materno referiram dificuldades de adaptação ao leite materno. Estes resultados são apresentados no Quadro IV. As razões mais apontadas foram as dificuldades na pega, referidas por $45,9 \%$ destas puérperas $(34 / 74)$, seguidas pelos problemas com os mamilos em $40,5 \%(30 / 74)$, a hipogaláctia, com $13,5 \%$ (10/74), e as dores, com 8,1\% (6/74). Em 35 puérperas, as dificuldades de adaptação motivaram a introdução de leite artificial.

\section{DISCUSSÃO}

Um total de 73 mães $(44,5 \%)$ das 164 mães inquiridas ou não receberam informação (62) ou esta foi insuficiente (11). Comparando com estudos publicados, em que apenas $13 \%$ das inquiridas referiram não ter recebido qualquer informação, ${ }^{3} \mathrm{o}$ resultado alcançado no presente estudo parece insuficiente, justificando a promoção do aconselhamento sobre aleitamento materno.

O facto de o questionário ter sido aplicado na maternidade, que foi simultaneamente o momento em que mais puérperas receberam informação (43,3\%), pode justificar, em parte, que os profissionais de saúde tenham sido as fontes de informação mais frequentes (o enfermeiro, citado por 54,3\%, e o médico, citado por $37,2 \%$ das mães). Estes dados divergem dos encontrados no único estudo consultado em que foi avaliada a informação sobre aleitamento. No estudo referido, os profissionais de saúde foram responsáveis pela informação sobre aleitamento em apenas $9 \%$ das inquiridas. ${ }^{3}$ Pode dizer-se que os profissionais de saúde tiveram um papel mais significativo no estudo actual, mas como se constatou, a informação foi prestada a um número menor de puérperas. Seria importante perceber se essas diferenças traduzem uma diferente abordagem da informação ou se resultam de um viés resultante do momento de aplicação do questionário.

Segundo as puérperas, os pontos mais positivos da informação recebida foram a clareza e a possibilidade de esclarecer eventuais dúvidas sobre aleitamento materno, classificados como «Muito Bons» ou «Bons» em $82,4 \%$ e $86,3 \%$, respectivamente; no entanto, o tempo despendido e o número de intervenções foram considerados insuficientes em $11,8 \%$ e $10,8 \%$, respectiva-

\begin{tabular}{|lrr|}
\hline \multicolumn{3}{|l|}{ QUADRO III. Razões apontadas para a escolha do leite } \\
materno e/ou do leite artificial. \\
Leite materno & & $(\mathrm{n}=156)$ \\
\hline Vantagens para o & Imunitárias & $73,1 \%$ \\
recém-nascido & Nutricionais & $63,5 \%$ \\
& Gastrointestinais & $4,5 \%$ \\
& Crescimento & $66,7 \%$ \\
& Psicológicas & $6,4 \%$ \\
\hline Vantagens para a & Recuperação pós-parto & $21,2 \%$ \\
mãe & Cancro da mama & $13,5 \%$ \\
& Psicológicas & $3,8 \%$ \\
& Contracepção & $4,5 \%$ \\
\hline Outras razões & Experiência anterior & $14,7 \%$ \\
& Prático e cómodo & $13,5 \%$ \\
& Mais barato & $3,8 \%$ \\
\hline Leite artificial & & $(\mathrm{n}=38)$ \\
\hline Razões & Dificuldades de adaptação & $92,1 \%$ \\
& Medicação materna & $7,9 \%$ \\
& & \\
\hline
\end{tabular}




$\begin{aligned} & \text { QUADRO IV. Dificuldades de adaptação ao aleitamento } \\
& \text { materno }(\mathrm{n}=74) .\end{aligned}$
\begin{tabular}{lc} 
Dificuldades de adaptação & Frequência \\
\hline Dificuldades na pega & $45,9 \%$ \\
\hline Problemas com os mamilos & $40,5 \%$ \\
\hline Hipogaláctia & $13,5 \%$ \\
\hline Queixas dolorosas & $8,1 \%$
\end{tabular}

mente.

De uma forma global, os Cuidados Primários de Saúde tiveram um papel pouco determinante na prestação de aconselhamento sobre aleitamento materno, uma vez que apenas $22,6 \%$ das puérperas foram seguidas no centro de saúde, para além das $6,1 \%$ seguidas no centro de saúde e no hospital. Estes resultados são consistentes com outros já publicados, de caracterização das puérperas do Hospital de Santo André, E.P.E., Leiria, em que apenas $16,4 \%$ das inquiridas foram seguidas exclusivamente no centro de saúde..$^{21} \mathrm{~A}$ maioria das puérperas $(56,1 \%)$ foram seguidas por obstetra particular, à semelhança do estudo referido, o que levanta questões sobre a informação e acessibilidade às consultas de Saúde Materna, bem como a imagem dos centros de saúde na área de influência deste hospital.

A prevalência de aleitamento materno foi de $95,1 \%$, com $76,8 \%$ das puérperas a fazer aleitamento materno exclusivo e $4,9 \%$ das puérperas a realizarem aleitamento artificial. Estes valores estão de acordo com os encontrados na literatura. , $^{2,3,11-13}$

Quanto à percentagem de puérperas a fazer aleitamento misto $(19,2 \%)$, trata-se ainda de um valor significativo, apesar de inferior ao encontrado na literatura, em que a introdução de pelo menos um biberão de leite adaptado variou dos 34 aos $53 \%{ }^{2,3,12,22}$ Contudo, como nem sempre foi possível aplicar o questionário no dia da alta, o valor encontrado pode estar falsamente diminuído.

Quanto às razões para a escolha do aleitamento materno, não se usaram hipóteses de resposta incorrectas, uma vez que o objectivo não era avaliar o conhecimento sobre as vantagens do aleitamento materno, mas sim conhecer as motivações para a sua escolha. Os resultados são consistentes com o descrito na literatura, onde ficou demonstrado que as vantagens para o bebé são mais conhecidas pelas mães, a maioria referindo as vantagens imunológicas, seguindo-se, por ordem decrescente, as vantagens nutricionais, gastrointestinais, de desenvolvimento e psicológicas. ${ }^{3}$

Comparando com outros estudos publicados, ${ }^{2,3,13}$ a hipogaláctia, que é geralmente a razão mais apontada para o abandono do aleitamento materno, foi menos frequente no presente estudo, surgindo apenas em terceiro lugar. No entanto, nos outros estudos a avaliação destes factores é feita decorridos um a seis meses após o parto, e não no puerpério precoce.

Uma vez que as dificuldades de adaptação ao aleitamento materno motivaram a introdução de leite adaptado em 35 puérperas e foram referidas por $47,4 \%$ das inquiridas a fazer leite materno, é fundamental dirigir o aconselhamento prestado, no período pré e pós-natal, à sua compreensão e estratégias de resolução.

A evidência científica refere como fundamental o apoio continuado na protecção, promoção e apoio ao aleitamento materno nos períodos pré e pós-parto. A maioria das «Dez medidas para o sucesso do aleitamento materno» necessita de ser implementada na maternidade e reforçada em todas as instituições que cuidam de mães e bebés, nomeadamente:

- Início precoce na $1 .^{\mathrm{a}}$ hora pós-parto, contacto pele a pele

- Não dar outros alimentos ou líquidos ao RN excepto por prescrição médica

- Não dar tetinas, chupetas, etc...

$\mathrm{Na}$ «Global Strategy for Infant and Young Child Feeding» 2003, OMS, refere-se que as mães têm direito a ajuda por profissionais com treino e competências, em aconselhamento em aleitamento materno, para a resolução das dificuldades na implementação do aleitamento materno. A escassez de profissionais com competências específicas (em aconselhamento em aleitamento), apenas 4 maternidades certificadas pela Iniciativa Hospital Amigo do Bebé no país e práticas enraizadas não eficazes no apoio à iniciação e manutenção do aleitamento (uso de biberão, tetina e chupeta), fazem parte dos obstáculos que as mães encontram para ultrapassar as dificuldades.

Nos últimos anos a DGS e algumas Administrações Regionais de Saúde (ARS) fizeram uma aposta na formação de «Conselheiros em Aleitamento Materno» em 
todo o país, mas são poucas as mães que têm apoio em aconselhamento em aleitamento materno, de acordo com as orientações das Boas Práticas em aleitamento materno.

Este estudo teve como principal limitação a dimensão e a forma de selecção da amostra, dado ter sido aplicado apenas durante quatro semanas consecutivas. A realização do estudo em vários períodos ao longo do ano, de forma aleatorizada, poderia resultar em resultados diferentes dos encontrados. Também o facto de o questionário ter sido aplicado por entrevista e não por autopreenchimento pode ter adicionado algum viés. Tentou-se minimizar esse efeito pela existência de um único entrevistador, que se limitava a ler o questionário. Outro dos pontos fracos deste estudo foi o facto de as variáveis escolhidas se referirem à percepção das puérperas sobre a informação recebida e as suas motivações ou dificuldades, ao invés de avaliar o verdadeiro conhecimento da informação.

Como ponto forte, destaca-se o facto de avaliar diferentes parâmetros da informação pré-natal, permitindo perceber onde é mais urgente melhorar. Destaca-se ainda o facto de caracterizar as dificuldades sentidas pelas puérperas no pós-parto precoce, possibilitando o planeamento do apoio pós-natal.

Perante os resultados apresentados, conclui-se que é necessário um reforço da informação prestada sobre aleitamento materno pelos profissionais de saúde durante o seguimento da gravidez, nomeadamente com mais intervenções desde as 20 semanas de gestação até ao parto, quer pelo médico, quer pelo enfermeiro. Essa informação pode ser complementada pela distribuição de folhetos informativos nas consultas de saúde materna, versando as várias vantagens do aleitamento materno, bem como aspectos práticos da sua implementação e abordagem das dificuldades mais frequentes.

Ficou demonstrado que quase metade das puérperas a fazer aleitamento materno revela dificuldades de adaptação, o que justifica a implementação de medidas de apoio. Os médicos de Medicina Geral e Familiar dispõem de várias oportunidades após a alta da maternidade para apoio ao aleitamento materno, nomeadamente nas consultas de saúde infantil, revisão de puerpério e visitas domiciliárias preventivas.

Tendo em conta a prevalência de dificuldades de adaptação ao aleitamento materno e a grande taxa de abandono do aleitamento até aos seis meses, propõe-se a avaliação posterior da prevalência de aleitamento materno aos 1, 3 e 6 meses, registando qual a alimentação do bebé nas últimas $24 \mathrm{~h}$, de acordo com as orientações da OMS. Propõe-se ainda o estudo dos factores associados ao abandono do aleitamento materno na nossa área de influência. Para tal, propõe-se a realização de um novo estudo, mas com uma amostra aleatorizada e mais abrangente, de forma a poder melhorar as medidas agora propostas.

\section{REFERÊNCIAS BIBLIOGRÁFICAS}

1. Horta BL, Bahl R, Martines JC, Victora CG. Evidence on the long-term effects of breastfeeding: systematic reviews and meta-analyses. Geneva: World Health Organization; 2007. p3-41.

2. Caldeira T, Moreira P, Pinto E. Aleitamento materno: estudo dos factores relacionados com o seu abandono. Rev Port Clin Geral 2007 NovDez; 23 (6): 685-99.

3. Sandes A, Nascimento C, Figueira J, Gouveia R, Valente S, Martins S et al. Aleitamento materno: prevalência e factores condicionantes. Acta Med Port 2007 Mai-Jun; 20 (3): 193-200.

4. Malcova H, Sumnik Z, Drevinek P, Venhacova J, Lebl J, Cinek O. Absence of breast-feeding is associated with risk of type 1 diabetes: a case-control study in a population with rapidly increasing incidence. Eur J Pediatr 2006 Feb; 165 (2): 114-9.

5. Turck D; Comité de Nutrition de la Societé Française de Pediatrie. Allaitement maternel: les bénéfices pour la santé de l'enfant et de sa mère. Arch Pediatr 2005 Dec; 12 Suppl 3: S145-65.

6. Klement E, Cohen RV, Boxman J, Joseph A, Reif S. Breastfeeding and risk of inflammatory bowel disease: a systematic review with meta-analysis. Am J Clin Nutr 2004 Nov; 80 (5): 1342-52.

7. Akobeng AK, Ramanan AV, Buchan I, Heller RF. Effect of breastfeeding on risk of coeliac disease: a systematic review and meta-analysis of observational studies. Arch Dis Child 2006 Jan; 91 (1): 39-43.

8. Martin RM, Gunnell D, Owen CG, Smith GD. Breastfeeding and childhood cancer: a systematic review with metaanalysis. Int J Cancer 2005 Dec 20; 117 (6): 1020-31.

9. World Health Organization, Unicef. Global strategy for infant and young child feeding. Geneva: World Health Organization; 2003. p1-30.

10. Taveras EM, Capra AM, Braveman PA, Jensvold NG, Escobar GJ, Lieu TA. Clinician support and psychosocial risk factors associated with breastfeeding discontinuation. Pediatrics 2003 Jul; 112 (1 Pt 1):108-15.

11. ONSA: Inquérito Nacional de Saúde - Continente 1998-1999. Lisboa: Ministério da Saúde. Instituto Nacional de Saúde. Observatório Nacional de Saúde; 2000.

12. Sarafana S, Abecassis F, Tavares A, Soares I, Gomes A. Aleitamento materno: evolução na última década. Acta Pediatr Port 2006 Jan-Fev; 37 (1) 9-14.

13. Lopes B, Marques P. Prevalência do aleitamento materno no distrito de Viana do Castelo nos primeiros 6 meses de vida. Rev Port Clin Geral 2004 Set-Out; 20 (5): 539-44. 
14. Dubois $L$, Girard M. Social determinants of initiation and exclusivity of breastfeeding at the population level: the results of the Longitudinal Study of Child Development in Quebec (ELDEQ 1998-2002). Can J Public Health 2003 Jul-Aug; 94 (4): 300-5.

15. Donath SM, Amir LH; ALSPAC Study Team. Relationship between prenatal infant feeding intention and initiation and duration of breastfeeding: a cohort study. Acta Paediatr 2003 Mar; 92 (3):352-6.

16. Su LL, Chong YS, Chan YH, Chan YS, Fok D, Tun KT, et al. Antenatal education and postnatal support strategies for improving rates of exclusive breast feeding: randomised controlled trial. BMJ 2007 Sep 22; 335 (7620): 596-603.

17. Merten S, Dratva J, Ackermann-Liebrich U. Do baby-friendly hospitals influence breastfeeding duration on a national level? Pediatrics 2005 Nov; 116 (5): e702-8.

18. Murray EK, Ricketts S, Dellaport J. Hospital practices that increase breastfeeding duration: results from a population-based study. Birth 2007 Sep; 34 (3): 202-11.

19. Mattar CN, Chong YS, Chan YS, Chew A, Tan P, Chan YH, et al. Simple antenatal preparation to improve breastfeeding practice: a randomized controlled trial. Obstet Gynecol 2007 Jan; 109 (1): 73-80.

20. World Health Organization Division of Child Health and Development.
Indicators for assessing breastfeeding practices. Geneva:World Health Organization; 1991.

21. Bacelo TM, Lopes MS. Antecipar a vida - consulta pré-concepcional caracterização das puérperas do Hospital de Santo André - Leiria. Rev Port Clin Geral 2009 Jan-Fev; 25 (1): 19-29.

22. Branco AS, Bastardo C, Albuquerque M, Oliveira G. Aleitamento materno: a prática hospitalar e o sucesso das medidas de implementação do aleitamento materno até aos 6 meses de idade. Acta Pediatr Port 2004; 35 (5-6) 441-5.

\section{CONFLITOS DE INTERESSE}

Os autores declararam não possuir conflitos de interesses.

\section{ENDEREÇO PARA CORRESPONDÊNCIA}

Nadina Sousa

Rua da Machinha, 386

2445-592 Moita MGR

nadinasousa@gmail.com

Recebido em 25/08/2009

Aceite para publicação em 05/11/2010

\section{ABSTRACT}

\section{BREASTFEEDING: PREVALENCE AND RECEIVED INFORMATION}

Objectives: To describe the information about breastfeeding received by mothers. To describe type of feeding given to the newborn during the stay in the maternity ward. To find the reasons that led to adopting or not breastfeeding and the main difficulties in its implementation.

Type of study: Observational, descriptive and cross-sectional.

Location: Obstetrics Department of the Hospital Santo André, E.P.E., in Leiria.

Population: Committed parturients in that department.

Methods: We applied a pre-tested questionnaire by direct interview, during four weeks between December of 2007 and January of 2008. We studied variables related to the mothers' characteristics, pregnancy follow-up, received information and type of feeding. We excluded mothers who refused to participate, those incapable of responding for linguistic reasons and the ones committed for late post-natal complications.

Results: 164 parturients were included of which $63 \%$ stated having received information about breastfeeding. The most frequent sources of information were the nurse and the doctor. Regarding how they classified the information the most positive aspects were the clarity and the possibility to clarify doubts. The time spent and the number of interventions were considered insufficient in $11,8 \%$ and in $10,8 \%$ of the cases, respectively. The prevalence of breastfeeding was $95,1 \%$ and the most frequent reasons for its choice were the benefits for the baby. Of all the breastfeeding mothers, $47,4 \%$ stated difficulties with its implementation.

Conclusion: This study shows the need to improve the information given by health professionals about breastfeeding. It identifies the information parameters that need improvement for planning the intervention during pregnancy and the post-natal period.

Keywords: Breastfeeding; Counseling; Prevalence. 